\title{
Giant Parasitic Fibroid Mimicking Gist: A Clinical Dilemma
}

\author{
Vilas Namdev Kurude ${ }^{1}$, Venkat Gitte ${ }^{2}$, Aastha Raheja ${ }^{3}$, Anamika Kejriwal ${ }^{4}$, Shruti Raut ${ }^{5}$
}

\begin{abstract}
Background: Parasitic fibroids are a rare type of fibroids without direct uterine attachment. They pose a diagnostic dilemma and often present atypically.

Case description: We report a rare case of large secondary parasitic fibroid in a 24 year unmarried female who presented with history of lump abdomen for 6 months. She had history of laparoscopic myomectomy done 2.5 years back for the same complaint with histopathology report suggestive of leiomyoma. On examination, it was found to be subserosal pedunculated fibroid. All the tumor markers were negative except CA 125 which was $225 \mathrm{IU} / \mathrm{mL}$. Exploratory laparotomy was done. Uterus was normal size and seen separately. Bilateral tubes and ovaries were normal. A mass of size $30 \times 22 \times 15 \mathrm{~cm}$, firm in consistency occupying all the quadrants of abdomen, was observed. It had no attachment to the uterus or to the bowel. Mass weighing $6.5 \mathrm{~kg}$ was removed completely and sent for histopathology. HPE report confirmed leiomyoma. Her postoperative period was uneventful.

Conclusion: If the patient had prior history of myomectomy and mass is separate from the uterus with its blood supply away from uterus, diagnosis of parasitic leiomyoma should be considered.

Clinical significance: During morcellation procedures, a thorough inspection and washing of peritoneal cavity must be carried out, and endoscopic bag should be used to prevent secondary parasitic leiomyoma.

Keywords: Case report, Morcellation, Myomectomy, Secondary parasitic fibroids.

Journal of South Asian Federation of Menopause Societies (2020): 10.5005/jp-journals-10032-1198
\end{abstract}

\section{INTRODUCTION}

Giant wandering fibroids are very rare and usually have atypical clinical presentation imposing challenge to diagnosis.

Uterine leiomyomas are the most common benign pelvic tumors in reproductive-age women. They are benign, monoclonal tumors of smooth muscle cells of myometrium with abundant extracellular matrix. Wandering or parasitic fibroids belong to type VIII of the FIGO fibroid classification and have no myometrial involvement and are without direct uterine attachment. ${ }^{1}$

\section{Case Description}

Parasitic fibroids are known for their rarity, but giant ones are very rare. Hereby, we report a case of giant secondary parasitic fibroid of $6.5 \mathrm{~kg}$ measuring $30 \times 22 \times 15 \mathrm{~cm}$ first time. A 24-year-old unmarried female came to gynecology outpatient department with chief complaints of lump abdomen for 6 months. It was initially small in size and gradually progressed to occupy the whole abdomen. Patient had no menstrual complaints. She had history of laparoscopic myomectomy done 2.5 years back for the same complaint with histopathology report s/o leiomyoma. Her general physical examination was normal.

On per abdomen examination, a large $30 \times 22 \times 15 \mathrm{~cm}$ mass was felt occupying all the quadrants of abdomen, smooth surface, regular margin, firm consistency, and nontender with restricted mobility. Lower limit of the mass could not be reached. On per rectal examination, similar mass was felt, and uterus could not be felt separately. No nodularity felt and rectal mucosa was free. Her routine laboratory reports were normal.

On magnetic resonance imaging of abdomen pelvis, uterus was normal size with large well-circumscribed lesion attached to
${ }^{1,3-5}$ Department of Gynecology, JJ Hospital, Mumbai, Maharashtra, India

${ }^{2}$ Department of Urosurgery, JJ Hospital, Mumbai, Maharashtra, India

Corresponding Author: Aastha Raheja, Department of Gynecology, JJ Hospital, Mumbai, Maharashtra, India, Phone: +91 8586032882, e-mail: aastha_raheja2000@yahoo.com

How to cite this article: Kurude VN, Gitte V, Raheja A, et al. Giant Parasitic Fibroid Mimicking Gist: A Clinical Dilemma. J South Asian Feder Menopause Soc 2020;8(1):49-51.

Source of support: Nil

Conflict of interest: None

the anterior wall of the uterus through a broad stalk suggestive of pedunculated subserosal uterine leiomyoma. Bilateral adnexa were found to be normal.

All the tumor markers were negative except CA $125(225 \mathrm{IU} / \mathrm{mL})$.

Exploratory laparotomy was done. Uterus was normal in size and seen separately. Bilateral tubes and ovaries were normal.

A mass of size $30 \times 22 \times 15 \mathrm{~cm}$, firm in consistency occupying all the quadrants of abdomen, was observed. It had no attachment to the uterus or to the bowel. Mass was highly vascular and seemed to have vascular supply from greater omentum with retroperitoneal neovascularization. Mass was removed completely. It weighed $6.5 \mathrm{~kg}$. Hemostasis was achieved, and mass was sent for histopathology. HPE report confirmed leiomyoma. Her postoperative period was uneventful, and blood transfusion was not required. Patient was discharged on postoperative day 10 , and at 6 month follow-up, she does not have any complaint, and no new mass was observed on USG (Figs 1 and 2). 

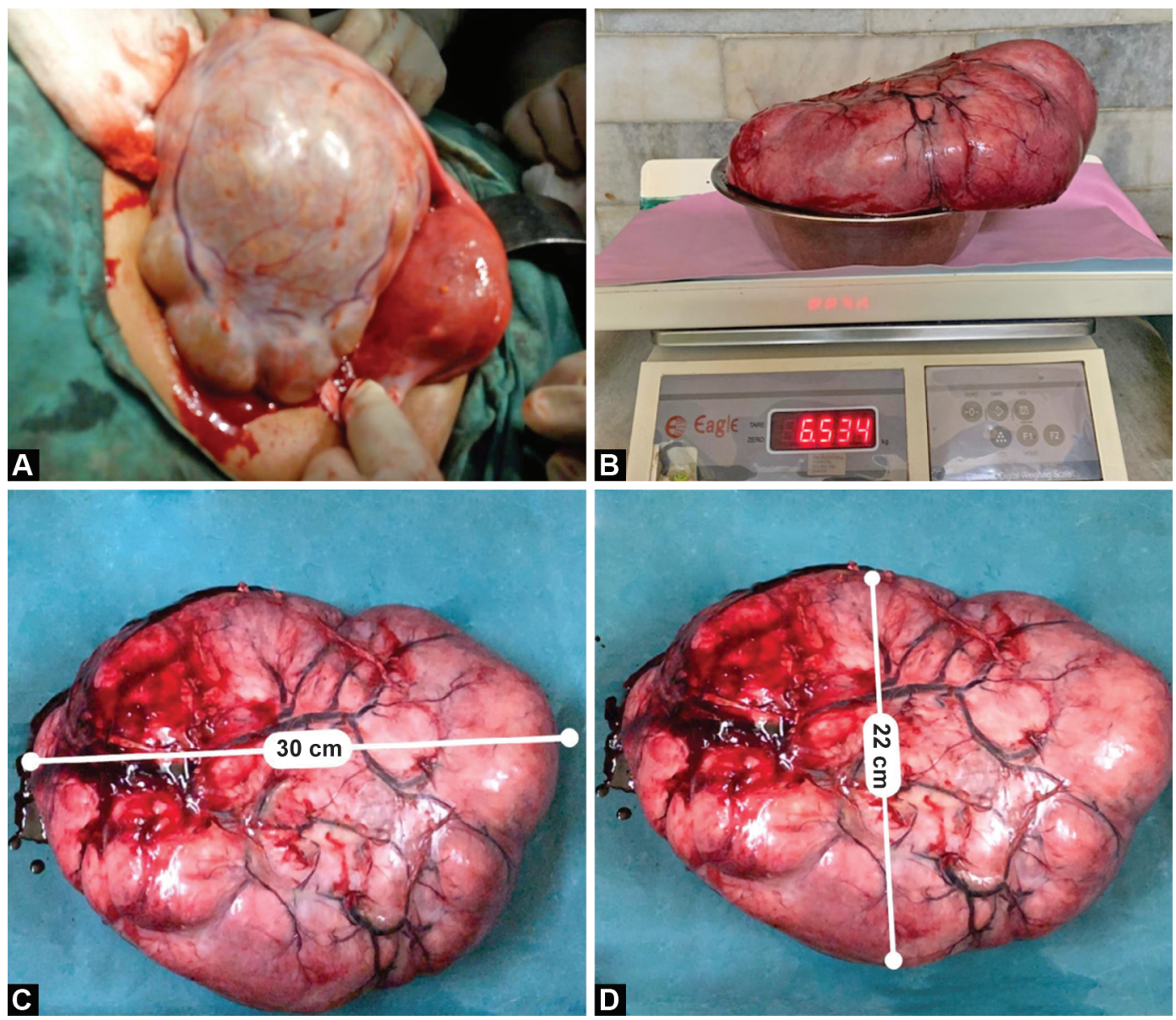

Figs $1 \mathrm{~A}$ to D: Giant parasitic leiomyoma weighing $6.5 \mathrm{~kg}$

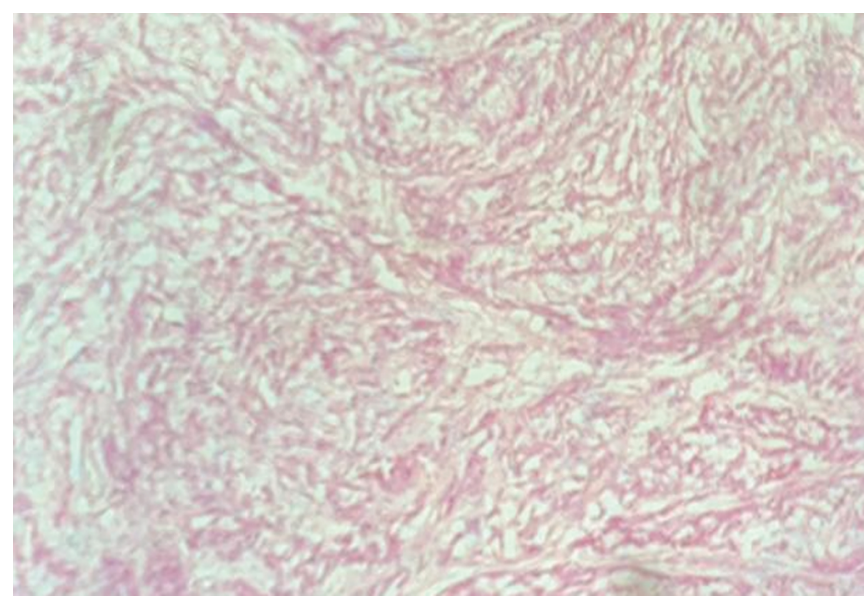

Fig. 2: Histopathology confirming leiomyoma

\section{Discussion}

The term parasitic leiomyoma was coined by Kelly and Cullen in $1909 .^{2}$ Parasitic myomas are a rare variant of pedunculated subserosal myomas. It has been suggested that if a pedunculated subserosal myoma develops a long stalk to become what is termed as a wandering leiomyoma, it can grow on and adhere to surrounding structures, such as omentum or broad ligament, and develop an auxiliary blood supply. ${ }^{2}$
Recent theory suggests "iatrogenic" parasitic myomas may be caused by the seeding of remnants of fibroid during morcellation at the time of myomectomy and hysterectomy.

Surgeons must be aware of this rare complication of myomectomy procedures.

Literatures have only few reported cases of parasitic leiomyoma. Largest reported parasitic leiomyoma up till now was by Osegi et al. in a menopausal lady. It was a primary parasitic leiomyoma weighing about $5.2 \mathrm{~kg}$. $^{3}$

Most of them reported in last few decades are secondary to increased laparoscopic procedures of the uterus. ${ }^{4}$

Kimberly and his colleagues reported 12 such cases. Ten of the 12 patients had history of abdominal procedures, and 8 had history of previous morcellation procedures. ${ }^{5}$

Lu et al. presented six cases of parasitic fibroid, and all of them had history of laparoscopic hysterectomy or myomectomy with power morcellation. ${ }^{6}$

Gaspare et al. conducted a retrospective study to show the development of parasitic fibroid after the application of a morcellator over 3 years in a tertiary hospital. Out of 423 women in who morcellation was done, $0.9 \%$ developed parasitic fibroid. It was concluded that morcellation is a risk factor for developing parasitic fibroid. ${ }^{7}$

Majority (93\%) of parasitic leiomyoma occurs in pelvis as in our case. ${ }^{4}$ 
Unlike our case, they are usually asymptomatic. ${ }^{8}$ The most common symptoms if present are pressure symptoms that include early satiety, bloating during eating, abdominal discomfort, and nausea. ${ }^{9-11}$ Our patient presented with lump abdomen and discomfort.

Although parasitic leiomyoma are rare tumors, they should be included in the differential diagnosis of pelvic or abdominal tumors in female. As prevention is better than cure, one should take care during morcellation procedure to avoid such complications.

\section{Conclusion}

Parasitic fibroids are rare and giant ones $(30 \times 22 \times 15 \mathrm{~cm})$ are very rare. Diagnosis of a parasitic leiomyoma should be considered if patient had prior history of myomectomy, mass is separate with blood flow away from the uterus. During morcellation procedures, thorough inspection and washing of peritoneal cavity must be carried out and endoscopic bag should be used to prevent secondary parasitic leiomyoma.

\section{Consent}

Informed written consent taken from patient.

\section{References}

1. Jones HW, Rock JA. Leiomyomata uteri and myomectomy. In: Jones HW, ed. Te Linde's Operative Gynecology. 11th ed., Philadelphia, (PA): Wolters Kluwer; 2015. pp. 658-662.
2. Kelly HA, Cullen TS. Myomata of uterus. Philadelphia: W B Saunders; 1909.

3. Osegi N, Oku EY, Uwaezuoke CS, et al. Huge primary parasitic leiomyoma in a postmenopausal lady: a rare presentation. Case Rep Obstet Gynecol 2019;2019:7683873. DOI: 10.1155/2019/7683873.

4. Sarmalkar M, Nayak A, Singh N, et al. A rare case of primary parasitic leiomyoma mimicking as ovarian mass: a clinical dilemma. Int J Reprod Contracept Obstet Gynecol 2016;5(2):545-548. DOI: 10.18203/2320-1770.ijrcog20160409.

5. Kimberly A, Nezhat C. Parasitic myomas. Obstet Gynecol 2009;114(3):611-615. DOI: 10.1097/AOG.0b013e3181b2b09a.

6. Lu B, Xu J, Pan Z. latrogenic parasitic leiomyoma and leiomyomatosis peritonealis disseminata following uterine morcellation. J Obstet Gynaecol Res 2016;42(8):990-999. DOI: 10.1111/jog.13011.

7. Gaspare C, Roberta G, Gloria C, et al. Parasitic myomas after laparoscopic surgery: an emerging complication in the use of morcellator? Description of four cases. Fertil Steril 2011;96(2):90-96. DOI: 10.1016/j.fertnstert.2011.05.095.

8. Mandal D, Dattaray C, Roy S. Spontaneous parasitic leiomyoma: a rare clinical experience. J S Asian Feder Obstet Gynaecol 2013;5(2):85-86. DOI: 10.5005/jp-journals-10006-1232.

9. Dashraath P, Lim LM, Huang Z, et al. Parasitic leiomyoma. Am J Obstet Gynecol 2016;215(5):665-e1-665-e2. DOI: 10.1016/j.ajog.2016.07.017.

10. Elagwany AS, Rady HA, Abdeldayem TM. A case of parasitic leiomyoma with serpentine omental blood vessels: an unusual variant of uterine leiomyoma. J Taibah Univ Med Sci 2014;9(4):338-340. DOI: 10.1016/ j.jtumed.2014.05.002.

11. Ghamande SA, Eleonu B, Hamid AM. High levels of CA-125 in a case of a parasitic leiomyoma presenting as an abdominal mass. Gynecol Oncol 1996;61(2):297-298. DOI: 10.1006/gyno.1996.0144. 